\title{
Architecture within a circular economy: Process mapping a resource-based design-bid-build project delivery system
}

\author{
Ahmed K. Ali
}

\begin{abstract}
In this paper, a novel method for integrating system thinking into architectural design by mapping its processes in a standard process modeling language was developed. The study aimed to structure a decision-support framework using process mapping workflows to incorporate sustainable building materials and resource-based design decisions into the conventional architectural practice. The author turned to other disciplines' knowledge bases, such as Business Information Technology (BIT), to develop a workflow for the Design-Bid-Build project delivery method (DBB). Mapping both the current and the proposed design processes, including their activities, workflow and decision nodes, was critical in defining roles, flow of information, and subsequent decisions. In this study, a qualitative methodology to capture the required knowledge from industry experts in resource-based design was utilized and then findings were integrated into a set of process maps to support the material decisions by the architectural project team.
\end{abstract}

This study establishes a system of information exchange to support the growth of the newly emerging industry of reuse stores and vendors. Through numerous interviews and knowledge-capturing sessions with experts from the building material reuse industry, it became evident that an absence of a system of information exchange exists. It is through this study that an overall system of information exchange will connect the links between the reuse industry and the AEC industry. The primary

\section{Permissions and copyright}

Authors retain copyright and grant the journal right of first publication with the work simultaneously licensed under a Creative Commons Attribution License that allows others to share the work with an acknowledgement of the work's authorship and initial publication in this journal (Attribution-ShareAlike).

Creative Commons Attribution 3.0 Unported (CC BY 3.0)

You are free to: Share - copy and redistribute the material in any medium or format. Adapt - remix, transform, and build upon the material for any purpose, even commercially. The licensor cannot revoke these freedoms as long as you follow the license terms.

Under the following terms: Attribution - You must give appropriate credit, provide a link to the license, and indicate if changes were made. You may do so in any reasonable manner, but not in any way that suggests the licensor endorses you or your use.

No additional restrictions - You may not apply legal terms or technological measures that legally restrict others from doing anything the license permits.

\section{How to cite:}

Ali, Ahmed K. 2017. "Architecture within a circular economy: Process mapping a resource-based designbid-build project delivery system ." Enquiry 14 (1): 48-61. outcome of this study is a structured process for design with resource reuse. The author conducted an extensive multi-year knowledge capturing process with constructive feedback from the industry experts.

Keywords: Architecture of Waste, System Thinking, Process Modeling, Resource-Based Design, Circular Economy.

\section{INTRODUCTION}

"Waste is worse than loss. The time is coming when every person who lays claim to ability will keep the question of waste before him constantly. The scope of thrift is limitless." -Thomas Edison

Solid waste from building construction and demolition activities is increasing every day, causing landfills around the world to reach their capacity. Adverse impacts of the deconstruction and demolition activities on the environment necessitates thinking about novel ways of reusing building materials in new construction (CIB 2002). Literature suggests that construction and demolition activities are the primary sources of solid waste worldwide. For example, demolition waste in England alone was estimated at 91 million tons in 2003 (Osmani 2008) and construction and demolition waste in the United States constitute about $40 \%$ of the total solid waste stream (USGBC 2003). An increasing body of knowledge regarding waste management and waste diversion from construction sites already exists, but almost no scholarship focuses on the role of the architect in reducing waste. Traditionally, the architect's primary focus has been on construction, with little thought devoted to un-building and deconstruction (Falk and Guy 2007). When looking today at the building and construction industry, it is striking to realize the enormous amount of waste being generated. The questions that arise for this problem are: what is the role of architects in improving waste prevention and reduction through design? How can salvage and reclaimed building materials be seamlessly integrated into new construction? What kind of information do we need to know? How can we evaluate and select reclaimed materials? What is the project delivery process?

The emerging building material reuse vendors and deconstruction contractors industry in the United States are faced with significant 
challenges from the absence of a "system" to streamline their business processes, establish a supply and demand chain, and connect them with designers and architects. Nevertheless, additional obstacles such as quantities required, storage, scheduling, and recertification add more pressure on this industry to get it off the ground. Successful case studies of materials reuse in building projects remain experimental, non-systematic, and widely differ from one to the other in incorporating building material reuse. Due to the scarce examples in the US, generalization of workflow and processes become a challenge. One recent successful example is the Big Dig House in Lexington, Massachusetts, as shown in Fig. 1. Designed by the architectural firm Single Speed Design, the house is a showcase for successful incorporation of steel beams and concrete slabs that were salvaged from the Big Dig project in Boston (Fettig et al. 2006). The processes of designing and implementing reused materials were unique and distinct due to numerous factors. For example, the owner of the house being a contractor on the Big Dig Project was instrumental in identifying the materials and securing the required quantity for the design team to work with.

\subsection{STATEMENT OF THE PROBLEM}

"Architects must begin to think about holes in the ground and about flows of materials." Wasting Away, Kevin Lynch (Lynch and Southworth 1990)

In their book Superuse: Constructing New Architecture by Shortcutting Material Flows, Netherland based architects 2012 Architecten (now renamed to Superuse Studios) imagined a holistic design scenario. Although it may seem unrealistic, it reflects much of the hypothesis that drives this research study. The scenario goes as follows:

Imagine that on the fringe of an industrial area they are demolishing an old rusty chemical plant. Huge steel tanks and pipes are cut into pieces and hoisted onto trailers to be brought to a scrap yard. There the metal is shredded into small fragments and loaded into trucks that transport the scrap to a steel factory a thousand miles away. They are fed into a blast furnace to be turned into blocks of raw material. They are rolled into sheets, which are formed into cylindrical shapes and transported to a building site which is all the way back, just a few miles from the place where the factory used to be. There they are carefully welded together to become part of the structure of a spectacular dance hall that the architect designed with curved steel walls. Their dimensions are similar to the ones of the tanks they stem from. A lot of effort and energy could have been saved if the design of that cool dance hall had included Superuse. (Hinte, Peeren, and Jongert 2007)

From this scenario, we can identify two approaches that deal with building materials: the conventional approach and the unconventional one. In his book, Building with Reclaimed Components and Materials, Bill Addis highlighted these two distinct approaches by clarifying two opposing design methodologies: the "normal design" and "design with reclaimed products and materials." He stated, "The design and procurement process for using reclaimed goods and recycled materials is entirely different from standard building practice. The world of reclamation,

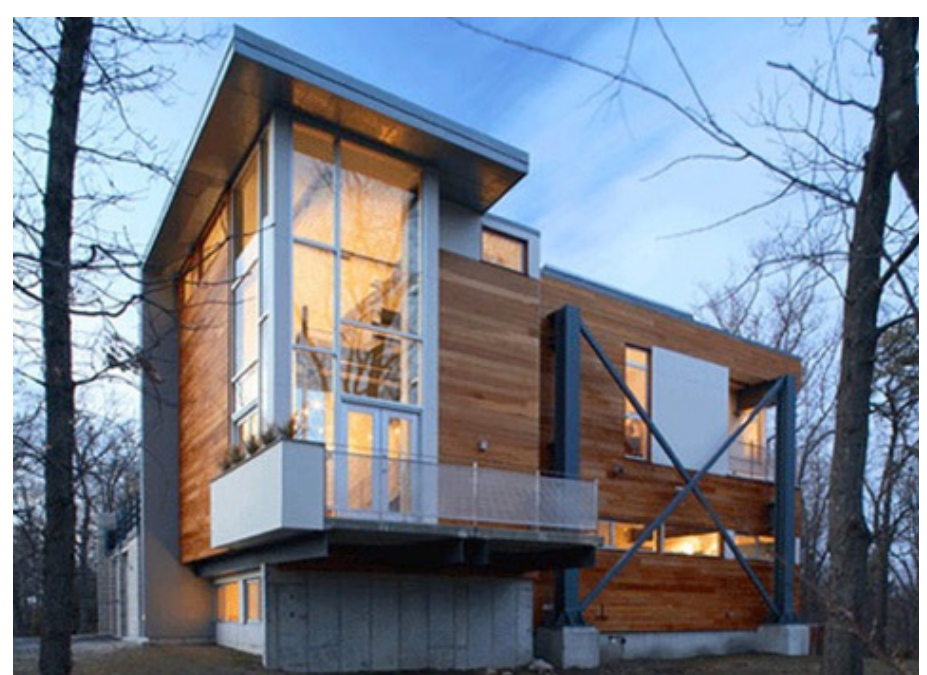

Figure 1. The Big Dig House, Lexington, Massachusetts, United States (Image credit: PBS.org. Apr 16, 2008)

reuse, and recycling is like a parallel universe that is virtually invisible to those familiar only with new building materials and components."(Addis 2006). Similarly, Taeke De Jong, a professor of ecology at the University of Technology in Delft, defined these two methodologies as "meansoriented design" and "goal-oriented design." The goal-oriented design is the conventional method where the goal (or building design in this case) is defined, and every decision serves to reach that goal. It is not until the design development phase that suitable materials will be sourced and purchased. The means-oriented design, on the other hand, is a process started by the means (or materials) available with a less strictly defined end goal. It is necessary to first source and acquires the materials before the design has reached the detailed stage. This process becomes more complicated due to its experimental nature and the potential failure in both sourcing materials and detailing the project. There must be time left for adjustments and changes throughout the entire process. De Jong stated that the process is never entirely one or the other, but that it is a matter of emphasis and that in architecture, a more heavily meansoriented design would be a refreshing approach.

Selecting and specifying materials and components for an architectural project is one of the most important and critical tasks of a design team. A building can be carbon neutral, energy efficient, or solar powered, but it will certainly be constructed with materials and components. These materials are usually extracted from raw resources, and through this process, they often leave a negative impact on the environment. The life cycle of most building materials and components are often longer than the life of the buildings themselves. Therefore, after demolition these materials and components end up in landfills. Some materials such as steel can be recycled by melting and reforming, but this ultimately consumes a substantial amount of energy, which could cost more than reusing the already extruded steel (Fletcher, Popovic, and Plank 2002).

Literature suggests that there is a growing interest in materials and resources conservation in the United States, especially with the growth 
of the green building practices (Saleh 2009). The United States Green Building Council (USGBC) identified six categories in the Materials and Resources (MR) section of the Leadership in Energy and Environmental Design rating system (LEED). One of the six categories is Resource Reuse (RR). Interestingly enough, a recent study focused on the cost of green buildings by Davis Langdon indicated that resource reuse is the credit least often achieved in the LEED rating system (Morris and Matthiessen 2007). According to recent studies, there are numerous constraints and barriers to resource reuse, generally due to the complexity of buildings, but perhaps the most important one is the lack of easily accessible information to the design team on resource reuse (Knecht 2004). One of the primary objectives of our study is first to capture the expert knowledge related to the process of reusing building materials and second, to build a Decision Support Framework (DSF) to assist the design team in considering, identifying, evaluating, and specifying reclaimed building materials and components in new construction.

Since the involvement of multiple stakeholders is essential to the success of the decision-making process, the decision support framework must view the decision as a "group decision-making" that involves potentially competing entities. This DSF would also address the environmental, economic, social, and cultural factors that are critical in making decisions and weighing them against those of conventional new building materials and components decisions. The DSF would include the following: 1) Identifying all possible significant constraints and barriers when using reclaimed building materials and components in new construction, 2) Developing a response to these limitations and obstacles, 3) Identifying all possible performance measures to the DSF, and 4) Applying decisionmodeling knowledge and systematic procedures.

\subsection{Fundamental Distinction Between Recycle and Reuse}

The work presented in this paper establishes the distinction between reuse and recycle that would structure the proposed paradigm shift in the traditional project delivery process. Recycling involves the processing of material waste in making new materials. That waste is considered to be part of the ingredients of making new materials which include recycled contents, and by allowing it to be part of the ingredients, two benefits might be achieved: first, the diversion of harmful waste from the solid waste stream, and second, the reduction in demand for virgin resources. There are currently four methods of legislation for recycling: minimum recycled content mandates, utilization rates, procurement policies, and recycled product labeling. As a result, manufacturers have to provide all pertinent data for these materials in a fashion that is similar to that of the non-recycled materials.

By recycling, the final product contains a percentage of what used to be called waste and that proportion and all other information related to the characteristics of this product are known to the architect. This data is widely accessible and ready to be specified for new construction similar to any other conventional materials. The recycled materials are cataloged with a standard set of data available, just like any standard construction product. In contrast, resource reuse and reclaimed materials require unique and specialized data and information that is customized for the source, quantity, and destination of the material.
This information is highly dynamic and constantly changing. Currently, the management of the supply chain for reused material does not easily support the acquisition of this information, which inhibits the implementation of reuse integration. The fact that there has been no legislation on resources reuse similar to those on recycling adds to the complexity of the issue.

\subsection{Design Process and Process Design}

Modeling a proposed and structured design process requires a thorough understanding of the difference between design process and process design. A typical design process might be described as a sequence of events that has a starting point and an ending point. The process is often investigative and sometimes circular, as new information becomes available. Design, in general usually begins with a precise definition of the problem but decisions concerning taste, choice, and sensitivity often rely on human value judgments. In architectural design, however, two forms of design processes are apparent: emergent processes as a result of forces and patterns, and constructed processes as an outcome of concepts (Plowright 2014). In contrast to a design process, a process design (or the design of a "process") refers to the planning and structuring of the routine steps of a process apart from the expected result. In process design, processes are treated as a product of design, not a method of design. The term "process design" originated from the industrial designing of chemical processes and with the increasing complexities of the information age, consultants and executives have found the term useful to describe the design of business, as well as manufacturing, processes (Korber 2002). According to William Miller, design is defined as "the thought process comprising the creation of an entity, and it consists of many smaller processes" (Miller 2004). Sub-design processes are described as detailed, smaller processes that are linked in a network of precedent relationships. Model formation, as defined by Friedman, can thus be divided into two parts: a decision model, which is a structure of data elements and mathematical relationships, and an information model that in our case could be the Building Information Modeling (BIM) database, which includes the parameters for the decision model (Friedman 2003). Like many other creative activities, the overall design process is linked to a path that is not always straight, and in fact is likely to include investigative subdesign processes. Some designers call this a "spiral" process because it has both a forward direction and a tendency for self-questioning along the way to ensure that it is going in the right direction. Literature suggests that there are five types of the architectural design processes known as follows:

- Linear: "Design process is a continuing sequence of basic linear steps" (Reekie 1972)

- Divisional: "Design process includes choosing the best solution out of several options of design solutions" (Jones 1992)

- Centralized: "There are no steps in the design process, everything is happening at the same time" (Lawson 2006)

- Cyclical: "Design process is a series of endless repetitive cycles" (Snyder 1970)

-Investigative: "Each step in the design process is based on a selective investigation process on options for ideas and solutions" (Kalay 1987) 
Any of the above design processes occur within the established project delivery methods known to the practice. The current trend is to move toward an Integrated Project Delivery method (IPD), however, the traditional Design-Bid-Build (DBB) process is still widely accepted as the industry standard and therefore this study was built modeling the DBB but acknowledging the shift towards IPD. In the next section, an explanation of the workflow of the traditional Design-Bid-Build method, followed by an attempt to model both the current workflow and the proposed resource based workflow, are presented.

\subsection{Building Materials Reuse and BIM}

Building Information Modeling (BIM) is the latest shift in the design and documentation methodology in the design and construction industry (Krygiel and Nies 2008). BIM is a single database that combines selected information related to a building from conceptual design to occupancy. There are many advantages to having one database that contains all information about the building's life cycle. Perhaps the most appealing advantages to the design team are the ability to efficiently coordinate design and construction documents, which greatly contribute to the reduction of information loss in traditional document management systems, and the ability to integrate with building product manufacturers and exchange product and materials information, which is the core of this study. BIM systems include, for instance, geometry, spatial relationships, light analysis, geographic information, quantities, and properties of building components (for example, manufacturers' details). BIM is anticipated to accommodate information from different project stakeholders added to the database throughout the building life cycle. Studies suggested that the building's end-of-life scenarios are often neglected from the current BIM practices (Akinade et al. 2017).

The proposed design scenario is envisioned as follows: An architect designs a new building while utilizing BIM. The proposed building is "dissected" as a process in BIM and an inventory of the building components is generated. This component inventory is archived for future reference and is used as input to the decision-support process. Concurrently, other buildings nearby or within (harvesting map) proximity either have been or are in the process of being de-constructed. An inventory of the available components from these de-constructed buildings is generated including essential information of the necessary decisionmaking attributes along with similar information from manufacturer reused product and salvaged warehouse stores and vendors. A home for all of the above information is called a "Virtual Repository" which is an online global library of reclaimed and salvaged building materials and components linked to all available physical repositories (reclaimed materials warehouses and stores) and constantly updated with available materials and all necessary information the design team needs for the design process. A simple representation of the process workflow can be seen in Figure 2. In the future, the previously mentioned BIM inventory from today's design will be activated when the building is de-constructed to provide an efficient mechanism for inventorying salvaged components. For the proposed new design, each component in the proposed building is compared with components in the virtual repository. Here comparisons are processed through the decisionsupport structure using the decision-making attributes. These attributes include but are not limited to assessment of age, possible fatigue and weathering of the reused component, structural integrity, history, appearance, size and dimensions, and ease of alteration. The matching process will be both direct and indirect based on the processing of the attributes. Direct matches are when a needed component, for example, a steel beam, is matched to an available component, for example, a steel beam. Indirect matching will occur when the evaluation of attributes identifies a salvaged component that may be adaptable for use as a new component (Roberts 2005). This can be referred to as creative repurposing, such as a set of exterior wall panels that could be reused as suspended ceiling panels. In addition the decision support process evaluates and compares other decision-making factors such as purchase costs, embodied energy, and transportation distance and cost. As part of the attributes for reused components, digital information like images, as-built drawings, de-construction drawings, specs, and other visual information of the component are accessible to the design team. The result is that the architect is now better informed concerning the option to reuse deconstructed building materials and components.

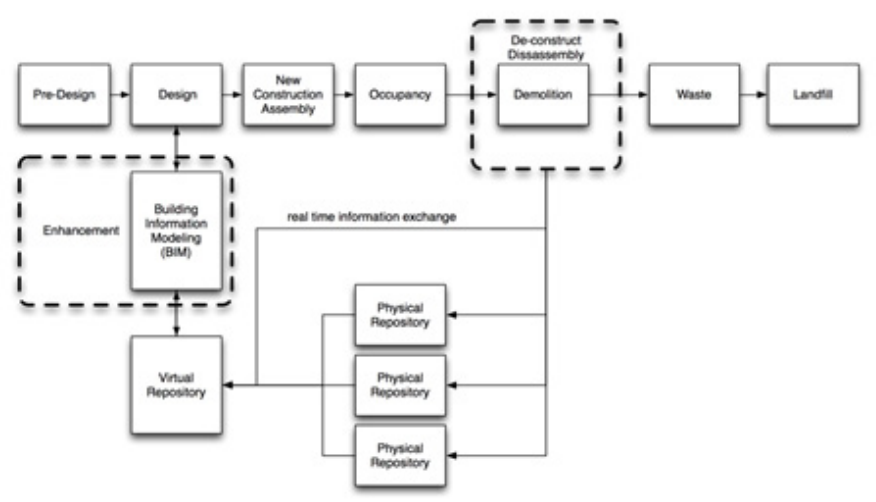

Figure 2. The Proposed Workflow Scenario between BMR and BIM (Author 2012)

\subsection{THE DESIGN-BID-BUILD PROJECT DELIVERY METHOD}

In the presented study herein, the primary focus is on enhancing the most utilized project delivery method in practice, known as Design-Bid-Build (DBB). The study illustrates, using process diagrams, both the current and the proposed resource-based design workflows in detail using two different modeling languages. It was inevitably realized through the research that incorporating resource reuse decisions into the DBB requires an early integration during the programming and pre-design phases. The overall DBB traditional design process typically starts with a program, creative idea(s), and an estimated budget, and then proceeds through several levels of development. Traditionally, in practice, there exist seven phases of a typical project, starting with abstract information gathering and conceptual design and leading through to the precise construction documents, construction administration, and finally culminating in occupation (AIA 2007). The phases as described by the American Institute of Architects (AIA) are set up to help guide the project in an orderly manner from start to finish so that there is little rework required. Reviews and approvals are necessary at each phase, and although there is a linear path from concept to completion, the reality 
of the process is investigative and circular. As previously discussed, any of the five-design process could occur within a project delivery method. But the nature of the DBB model phases requires the maintenance of an investigative approach while moving from one phase to the next. The first phase of the design process is called the pre-design or programming phase, which helps the architect collect all of the pertinent information about the project, such as program, budget, existing conditions survey, measure existing structure, and zoning code allowances for the site, on which the following design phases will be based. Deliverables are expected at the end of each phase, which become inputs to the next phase. The entire process is initiated through communication between a prospective client and an architect. At this time, the architect typically asks the client about the program or intended use of the proposed building, proposed budget for the project, location of the proposed project, and expected time frame for completion. This information represents the primary critical inputs to the pre-design or programming phase. This information is mostly quantifiable, with variables such as program, size, budget, location, and schedule. In this paper, only the mapping of the schematic design (SD) phase is discussed, as other phases of the process were documented in previous studies (Ali and Badinelli 2016). Although the DBB workflow is well established within the design and construction industry, no attempt had been made to model it in a standard modeling language. One of the significant contributions of the study is using standard modeling language to map the established and proposed DBB workflows.

For such a system to be useful it must be integrated into the building design process and allow the design team to carefully select building materials. These materials should not only contribute to the aesthetics and structure of the design but also reduce the building's waste when demolished, making the most of the life cycles of materials. By helping designers deliver the most viable design in terms of minimum waste generation on site, the building design and construction team as well as the client and contactors may benefit from profit increase (Kibert 2007). Other benefits include reducing the need to extract raw materials which conserves natural resources; creating employment and training opportunities; and developing local businesses that use the materials diverted from landfills and supply useful materials to building materials yards, recycling centers, and remanufacturing enterprises, creating additional jobs and community revenue as described below in detail. According to the USGBC, material and resources reduction primarily has three main benefits: Environmental, Economic, and Community.

\subsection{RESEARCH METHODOLOGY}

This study utilized a qualitative, grounded theory approach using an inductive mode and an intensive, open-ended and iterative process that simultaneously involved data collection, coding (data analysis), and memoing as a method for theory building (Wang and Groat 2013). The author used a knowledge-capturing approach from a medium sample of experts (61 participants in the first phase and 18 in the following phases) involved in the areas of architectural design with resource reuse, design for disassembly, and building deconstruction. The knowledge-capturing process was conducted through a multi-phase online questionnaire, face-to-face interviews, and structured Delphi focus groups. The knowledge captured was compared to the data extracted from the literature and case studies to form a consistency check. Findings from the qualitative analysis were evaluated through a triangulation method to test the validity of the proposed design workflow. The proposed framework constituted an effort to collect, organize and present available knowledge on building materials and resource reuse in a readily usable form. The number of attributes and variables in the resourcebased design process was overwhelming, therefore, a standard mapping language was utilized to streamline a paradigm shift within the typical architectural design process. The preferred solution was therefore ultimately based on trade-offs; weighing these trade-offs in a rational and explicit method was necessary. Some inputs to this framework emerged from personal interviews, analysis of selected case studies, and online surveys, which helped in identifying the evaluative categories. Each category contained a set of variables that were considered and integrated into the framework. The proposed workflow intends to reverse the design process and the conventional approach of specifying materials to building and will assist the design team to design around available and limited resources. The design of this research was based on a multi-phase inquiry process. These phases include the following:

- Phase 1: Information gathering and data collection

- Phase 2: Open-ended questionnaires and surveys

- Phase 3: Data analysis, reduction and coding

- Phase 4: Forming of categories (Descriptive)

- Phase 5: Looking for and comparing of patterns and procedures in literature and past experience (Analytical)

- Phase 6: Cross checking the accuracy of findings

The following section describes in detail how this framework would be built and what components would make its structure.

\subsection{Building the Framework}

Although the integration of building materials reuse to the DBB project delivery provides promising benefits to reduce waste in the building industry, it also adds new challenges to the already complicated design process. To better understand this study's approach to dealing with these challenges, one must first understand the components of this framework. The architectural design framework consists of a process model. The DBB process diagrams are integrated with the building material reuse workflow to form "the new process model," which is a series of activities that contains critical decision processes at every decision node. A knowledgebase that will support these critical decision processes is described in the following section.

\subsection{Building a Knowledgebase}

A knowledgebase is the core which supports the decision making process. A knowledgebase is defined as: " A database containing tacit knowledge (which is knowledge that is difficult to transfer to another person by means of writing it down or verbalizing it) in the form of formally coded facts and if-then-else decision rules." (Rhem 2006) A 
structured knowledgebase will support the critical decision processes, which form a series of activities in the new proposed process model. This knowledgebase consists of two main elements, Explicit Knowledge and Tacit Knowledge (which then can be transformed into explicit knowledge). Explicit Knowledge is knowledge that has been articulated and more often captured in the form of text, tables, diagrams, and product specification among other things. In this study, we will refer to explicit knowledge as the "computerized data and information" or "database" which in turn consists of Building Information Modeling (BIM) and the proposed Virtual Repository of Building Material Reuse (Materials Marketplace). Tacit Knowledge is the knowledge that is hard to transfer to another person by means of writing it down or verbalizing it because it resides in the minds of individuals and takes the form of insights, intuitions, and inspirations (much of the work of architects) (Rhem 2006). It can be represented as design objectives, design concepts, and human knowledge in resource reuse and sustainability. We have to understand that the latter form of tacit knowledge is the leading resource in qualitatively structuring the building material reuse virtual repository. Fig. 3 illustrates the knowledgebase structure and the relationship among its elements and components. In the study reported herein, data and information specifically related to building material reuse were captured, identified, and organized into a framework for the building design process. Ultimately, this study would eventually lead to a computerized database, though this is beyond the scope of the current work. The database is envisioned as an external source of knowledge that will be linked to a BIM database. The inclusion of BIM as a supporting tool will help connect with the IT professionals, as this diagrammatic process model is actionable and fundamental in constructing the database. The author suggest that a national organization such as the US Materials Marketplace managed by the United States Business Council for Sustainable Development (US BCSD) should assume standards for this knowledgebase. The next section will explain the process of capturing the required knowledge through a qualitative research methodology.

\subsection{KNOWLEDGE-CAPTURING PROCESS}

The knowledge-capturing process of this research involved using a Delphi method in the opinion-gathering sessions. The strategy for proposing the new model was based on first modeling the current DBB project delivery method using UML diagrams. Second, to present these initial UML diagrams to the study participants as part of the opinion-gathering sessions to solicit their feedback on the existing workflow. Third, is to incorporate their feedback into a new set of detailed BPMN maps then present it to them again to confirm findings. The study participants were assigned to two focus groups that maintained anonymity, meaning that the members were individually asked the same set of questions in every round of the Delphi process, without disclosing their identities to others. Consequently, participants did not have to worry about being forced to a final outcome in the first round of the opinion gathering session. They had the opportunity in the following rounds to modify their answers in light of the responses from other participants or stick with their original opinions. Rounds of these opinion-gathering sessions were conducted until the group reached a consensus. The same set of questions was sent to other stakeholders who expressed interest in participating in the study but who could not attend the actual group sessions. After the first round of interviews, the author organized, coded, and analyzed the responses and then prepared a second round of questions which were conducted through an online survey tool. The author conducted three phases of the knowledge capturing process, as described below, including surveys, questionnaires, and interviews, as well as information on the number of participants and responses, duration of surveys, formation of the expert panels, and questions presented. Participants in the study were drawn from diverse stakeholders who had been exposed to design with reuse and were organized in seven panels as shown below in Table 1.

- Phase 1: Preliminary Questionnaire - Pre-Conference:

The first phase of the knowledge capturing process started with an initial forecasting questionnaire. Two primary goals were set for the proposed questions: one, to get general and diverse opinions from all possible building stakeholders on the research problem, and two, to solicit a focus group from the industry experts to carry forward the Delphi process. Invitations were sent to 138 prospective stakeholders who were then divided into seven panels. Each panel included a number of industry experts related to the building design and construction industry in general and building material reuse in particular. The panels were organized as follows: Academics and Researchers (20), Architects and Designers (30), Deconstruction Contractors (19), Government Agencies and Building Officials (18), Materials \& Resources Technical Advisory Group at USGBC (MR TAG) (13), Salvage Vendors and Reuse Stores (19), and Case Studies Architects (19). The actual number of participants was 61.

- Phase 2a: Face-to-Face Interviews - Post Conference:

Following the solicitation request from the preliminary forecast questionnaire, two groups of participants were identified for further data collection. The first group confirmed attendance to the BMRA biannual conference (Table 1) and the second group were not able to attend the conference but remained interested in participating in the study. The number of interested participants from the first group was 15. However, only nine actually participated in the face-to-face interviews.

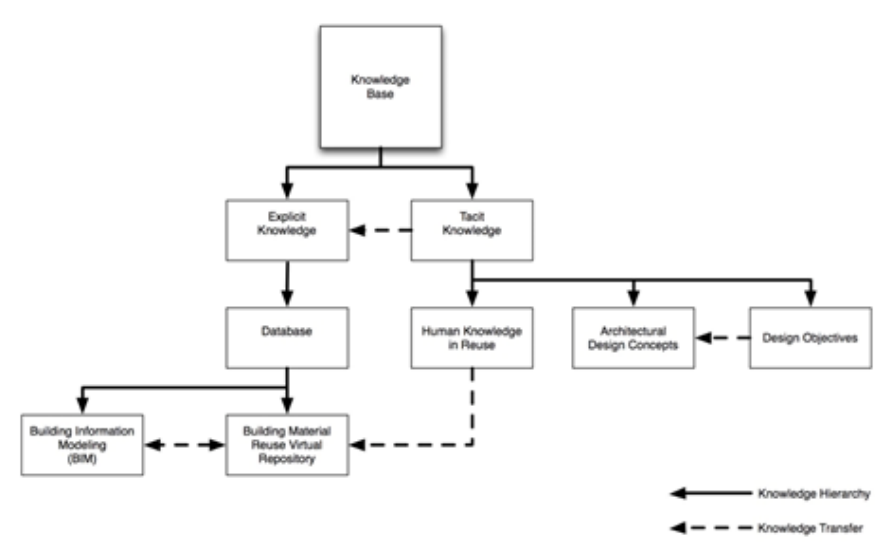

Figure 3. Knowledgebase Structure in Building Material Reuse (Author 2012) 
This reduction in number occurred due to scheduling conflicts and availability of individuals. However, the number of actual interviews was satisfying to the research sample. The structure of the interview sessions was designed to collect experts' opinions efficiently and to structure the findings. The knowledge capturing process was carefully planned to maximize the quality of data, and the information gathered through the use of the preliminary UML process maps.

- Phase 2b: First Round of Delphi Study - Post Conference:

The second phase of the knowledge capturing process was composed of two steps: a) the face-to-face interview and b) the virtual modified Delphi group. This group of stakeholders couldn't attend the conference but expressed interest in participating in the Delphi study. The virtual Delphi focus group was asked to respond (through an online survey tool) to the same questions presented to the face-to-face group. The group was formed from a panel of 19 members (only 9 were able to finish the survey) and represented diverse stakeholders from the building and construction industry as follows: Architects (4), Online Marketplace Founder (1), Reuse Store Owner and BMRA Secretary (1), Academic \& Community Development Advocate (1), Distributor, Contractor, Trainer, \& Consultant (1) and Academic \& Architect (1).

- Phase 3: Second Round of the Delphi Study - Post Conference:

The decision was made to end the knowledge capturing process and the Delphi process after Phase 3 , based on a consensus reached among the research focus group. This phase utilized again an online survey system to interact with the 18 members of the focus group. The two Delphi groups (nine members of the face-to-face panel and nine members of the virtual) were combined into one panel. This panel was composed of the following stakeholders: Deconstruction Contractor and Reuse Store (2), Government Agent and Advocate (1), Community Development and Deconstruction Contractor (1), BMR Consultant and Virtual Store Owner (2), Architects (6), Researcher and BMRA President (1), Research Architect (1), Reuse Store and BMRA Secretary (1), Academic \&Community Development Advocate (1), Distributor, Contractor, Trainer, \& Consultant (1), University Professor (1).

Invited participants were asked if they were interested in joining a Delphi Focus Group for further rounds of data collection and committing to further inquiries. Two panels were formed based on their interest as shown in Table 2. The 18 members of the Delphi Focus Group represented a diverse cross section of building materials and construction stakeholders. The Delphi focus groups were combined to one expert panel where eight members were practicing architects.

\subsection{The Delphi Method}

The Delphi method, as illustrated in Fig. 4, is a group decision-making technique developed in the early 1950s by Rand Corporation in California. The Delphi method seeks to achieve a consensus among group members through a series of questionnaires and data mining processes (Linstone and Turoff 1975). This series of questionnaires is conducted in two or more rounds and provides the participants in the second round with the results of the first round so that they can alter their original assessments if they want to, or stick with their previous opinions. Because the survey is done anonymously, no member was identified by his or her opinion to the others, thereby eliminating any possibility of coercive effects of interpersonal relationships (Woudenberg 1991).

One particular idea that reached consensus in this study of diverse stakeholders was that the design team should decide upfront if they want to implement resource reuse and come at the early stages of design development, having already identified areas of the building that they want to finish with reused materials or components, and with some notion of what type of materials they are looking for. Designers should take the main responsibility in putting reuse into the design and then recognize the need to help with the sourcing process. If the design team finds/identifies a source for salvaging, they can hire a deconstruction contractor to extract the needed materials and the materials can be stored until construction begins. The following elements were the decision model parameters identified by the focus group: availability of material in quantities, at times, and at costs necessary to meet project parameters; usefulness of materials; finish; performance; and function. The identified key stakeholders were: owner, architect, contractor, and engineer, in that order.

\subsection{Standard Modeling Languages}

Following several attempts to map the traditional project delivery method using bubble diagrams (known as a conventional method in architectural design), we realized that a standard modeling language was essential to map the resource-based design process. It was critically important to follow a consistent, representational repertoire and to build a common understanding with both the information technology and information systems domains. Using sketch and bubble diagrams to describe conceptual ideas and organization of spatial relationships is a common practice by architects and designers. As such, at the beginning of this study, the researcher, whose background is in architecture and

\begin{tabular}{|l|l|l|}
\hline Panel & Building Materials and Construction Sector & \# Of Invited Experts \\
\hline P1 & Salvage Vendors and Reuse Stores managers & 19 \\
\hline P2 & MR Technical Advisory Group at the USGBC & 13 \\
\hline P3 & Government Agents & 18 \\
\hline P4 & Deconstruction Contractors & 19 \\
\hline P5 & Architects and Designers & 30 \\
\hline P6 & Academics and Researchers & 20 \\
\hline P7 & Analyzed Case Studies (Architects) & 19 \\
\hline & Total Invited Participants & $\mathbf{1 3 8}$ \\
\hline
\end{tabular}

Table 1. Formation of external subject Expert Panels (Author 2012)

\begin{tabular}{|l|l|l|}
\hline Panel & Name of the Panel & \# Of Participants \\
\hline P1 & Delphi Focus Group (Face to Face) & 9 \\
\hline P2 & Delphi Focus Group (Online) & 9 \\
\hline & Total & $\mathbf{1 8}$ \\
\hline
\end{tabular}

Table 2.Delphi Focus Group Panels (Author 2012) 


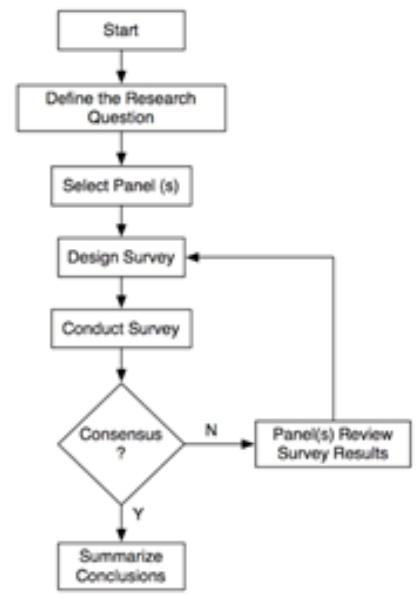

Figure 4. Delphi Process Workflow throughout Data Collection (Author 2012)

design, started to use the same approach to identify relationships and workflows between design processes. Later, and after feedback from experts in Business Information Technology (BIT), that approach revealed itself as insufficient and confusing. That discovery led to an extensive study of the available BIT modeling languages, understanding their advantages and capacities, then applying that modeling language into the research and the core work of this study. Fig. 5 shows an early attempt to model a proposed resource-based design scenario workflow. After carefully studying the available modeling languages such as UML, IDEF, and BPMN, we found that each has capabilities and limitations. We initially adopted the Unified Modeling Language (UML) in mapping the current traditional project delivery method (DBB) and the activity diagram of the proposed building material reuse workflow. However, after further investigations, other modeling languages, such as the Business Process Modeling Notation (BPMN) appeared to address critical details in the process. Literature suggests that process modeling should consist of static and dynamic elements. For static components of a system, especially the architecture and design of a system, there are design patterns (which later were extracted from the data collection phase). The dynamic aspects of a system are abstracted and captured as process patterns. Using patterns in the modeling of systems helps keep the process standardized, and more importantly, minimizes repetition in the system design. Events were used to communicate a relationship between a context, a problem, and a solution, and bring in and reuse the previous modeler experience. An example of mapping the flow of activities in the DBB process that typically includes a sequence of activities and processes is shown in a UML map of the Schematic Design phase (SD) (Fig 6).

\subsection{Unified Modeling Language (UML)}

Initially, the author selected the UML language to map the current DBB project delivery method. UML is known as an easy language to understand; its activity diagrams are simple to learn and are similar

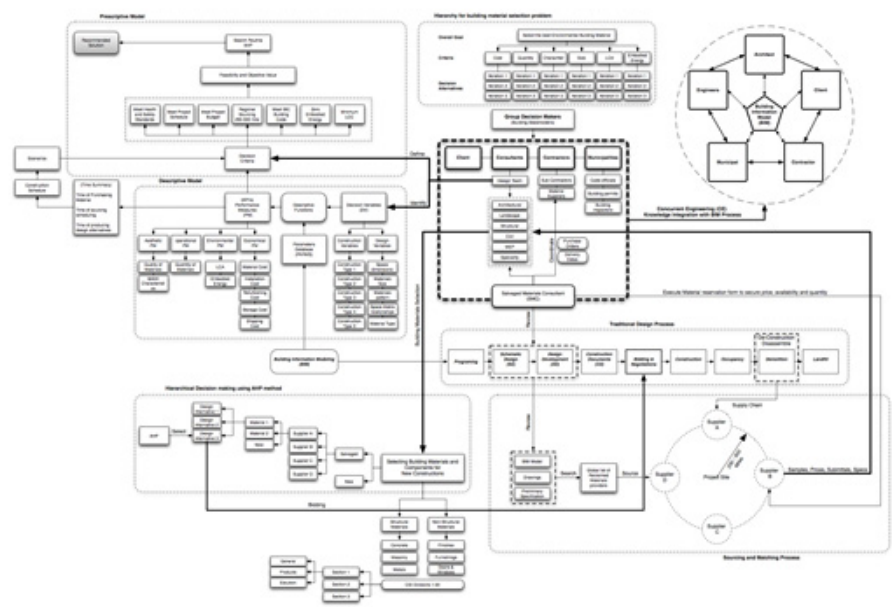

Figure 5. Early attempt to model a resource-based design process workflow (Author 2012)

to flowcharts (Rhem 2006). UML activity diagrams are graphical representations of a workflow of stepwise events and actions with support for choice, iteration, and concurrency. Activity diagrams are also used to describe the business and operational step-by-step workflows of components in a system. The diagrams show the overall flow of control and are constructed from a limited repertoire of shapes connected with arrows, as shown in Fig. 6 . The most common representation symbols are rounded rectangles representing activities; diamonds representing decisions; bars representing the start (split) or end (join) of concurrent events; and arrows that run from the start toward the end, representing the order in which activities happen. Decisions are represented as "nodes" where each decision would have information inputs. Decision needs should be specified as alternatives, decision variables, Key Performance Indicators (KPIs), and parameters. The component of the decision model is beyond the scope of this study.

\subsection{Business Process Modeling Notation (BPMN)}

As the complexity of the process maps increased due to feedback from our research participants, a more detailed language was needed to address information such as responsible parties, reference maps, and phase identification. We found the Business Process Modeling and Notation (BPMN) language to be useful in revising the initial DBB design processes maps using UML. BPMN is a graphical representation for specifying business processes in a process model. BPMN language allowed us to include more details in modeling, such as project phase, responsible stakeholder, and a cross-referencing system similar to construction documents standards. In the revision of the workflow, a thorough review of all the boxes in the knowledge and data section was considered in a hierarchical structure. The specification of knowledge elements went from general to specific in a hierarchal method. A sample representation of a BPMN map can be seen in Fig. 7, illustrating the SD phase. 

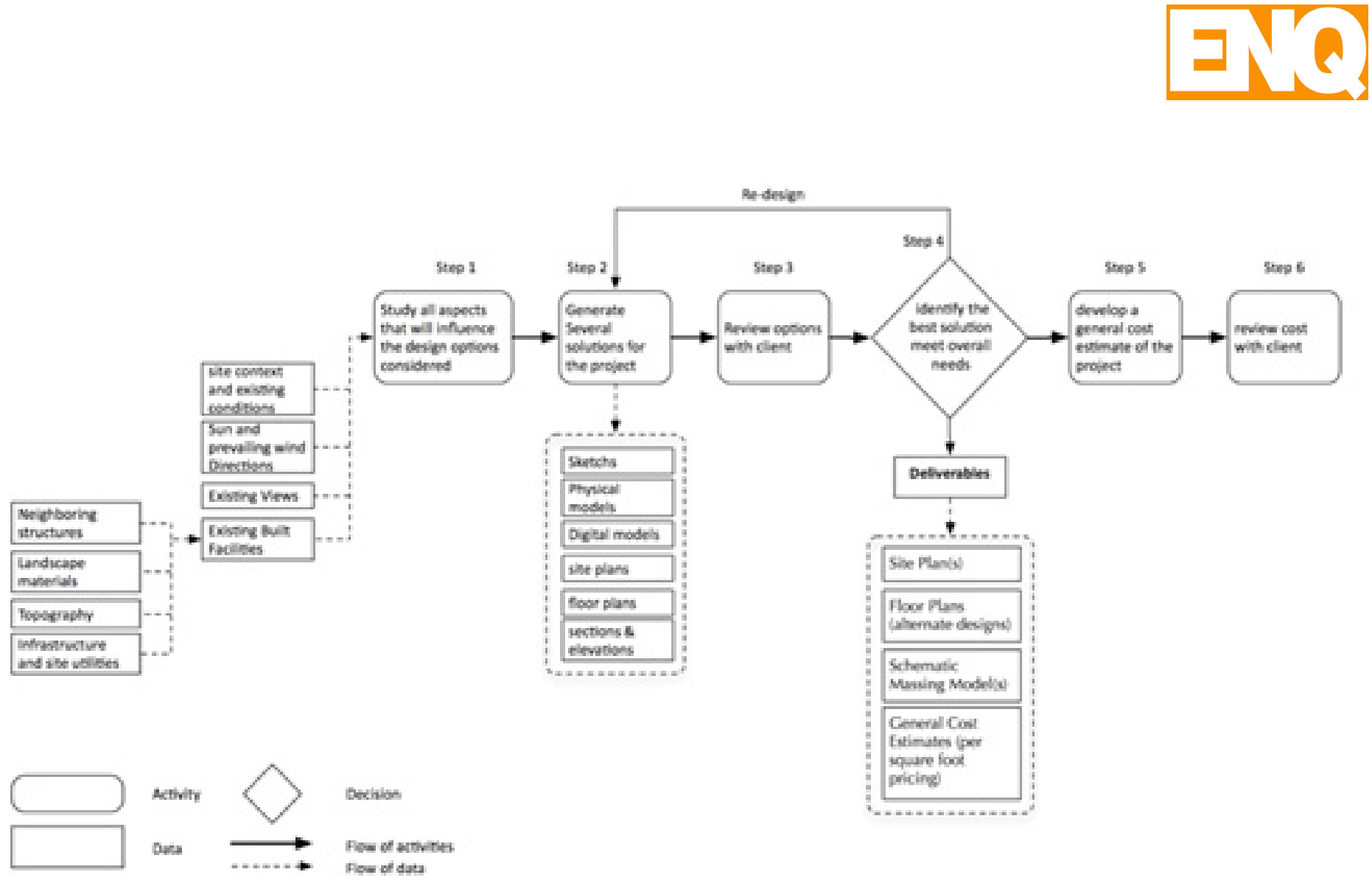

Figure 6. UML process map of the DBB schematic design (SD) phase. Source: (Author 2013)

The new process maps developed would allow the project team to understand the overall resource-based design process, identify the information exchanges that will be shared among multiple stakeholders, and define the various processes to be performed. The use of process mapping standard language with BPMN allows the project team to effectively plan for reuse integration while keeping consistent representation for future implementation. These process maps will also serve as the basis for identifying other important implementation issues including contract structure, BMR deliverable requirements, information technology infrastructure, and the selection criteria for future team members. The process mapping procedure for the Building Materials Reuse is needed to understand the workflow of integrating the value to the traditional design process. Initially, an overview map representing the sequencing and interaction between the primary BMR phases on the project was developed. This allows all team members to understand how their work processes interact with the processes performed by other team members. After the overview map is developed, the team members responsible for each detailed BMR process are developed and presented as more detailed process maps. For example, the highlevel map will show how the DBB project delivery phases are sequenced and interrelated. A detailed map will show the detailed phase process that will be performed by a project stakeholder. A fully detailed and enlarged set of the developed BPMN maps is available from the author for testing. These maps could be used as templates by the project team in the early phases of project planning to identify activities, workflows, and decisions.

It is important to note that the development of the BIM Project Execution Planning Guide by the Pennsylvania State University was a major milestone in setting the standards for strategic planning by the project team in the early stages of design. This guide was a product of the BIM Project Execution Planning buildingSMART Alliance Project (CICRP 2010). The guide was developed to integrate BIM into the project delivery process effectively. The core modeling and information exchange concepts have been designed to complement the long-term goals of the bSA in the development of a standard that can be implemented throughout the AEC industry to improve the efficiency and effectiveness of BIM implementation on projects. The BIM Project Execution Planning Guide illustrated processes using BPMN, and was a major guide in the development of the new resource-based design process maps presented in this paper. By adopting the same modeling language and integrating the mapping of both processes, the project team can quickly identify the required data and information exchange.

\subsection{BUILDING THE PROCESS MODELS}

The proposed resource-based design process model is an effort to collect, organize and build relationships between activities, processes, 
knowledge, data, and information in a standardized workflow language from start to finish. The strategy for the appropriate use of the BPMN process models is based on the willingness of the project design team, in particular architects, to adopt a systematic approach to their traditional design process. This approach must incorporate the use of the BPMN maps as a set of blueprints in order to plug in roles, activities, and resources. Since the methodology of the mapping systems was based on a business information technology standardized language, translation to computer programming is easy to communicate with IT professionals.

The value-added component of resource reuse to the current DBB process required a seamless integration with the design process. The presented UML activity maps illustrate the captured knowledge from both literature and experts. Several project stakeholders and consultants are involved in the activities and processes related to design, demolition, and procurement. Some of the activities are performed concurrently and some, sequentially. The initial UML activity maps represented some of these relationships in the SD phase. The SD phase is presented on three detailed level maps based on the complexity of a project. First is
Level 0, a traditional DBB process modified from UML to BPMN. Second is Level 1, with a new BPMN process, including preliminary resource reuse activities. Third, Level 2 has a new BPMN process, including detailed resource reuse processes (Fig. 7 and 8 ). The process maps were built using layers of information and decision processes. The previous UML activity maps represented some of these relationships in the SD phase. To structure the building material reuse workflow and matrix of relationships between processes, information, and resources, the author adopt a standard modeling procedure. For the purpose of this research, Unified Modeling Language (UML) was initially used and represented by activity diagrams (Ali and Badinelli 2016).

\subsection{Traditional DBB Schematic Design Process Level 0 (SD2a)}

Traditionally, this phase includes developing several preliminary design iterations for review and selection. Some important activities take place here, such as reviewing the project program with the client, developing spatial relationships, providing preliminary design concepts, obtaining input from a landscape architect, presenting design ideas to the

Figure 7. Resource-based schematic design process level 1 (\# SD2b). Source: (Author 2016)

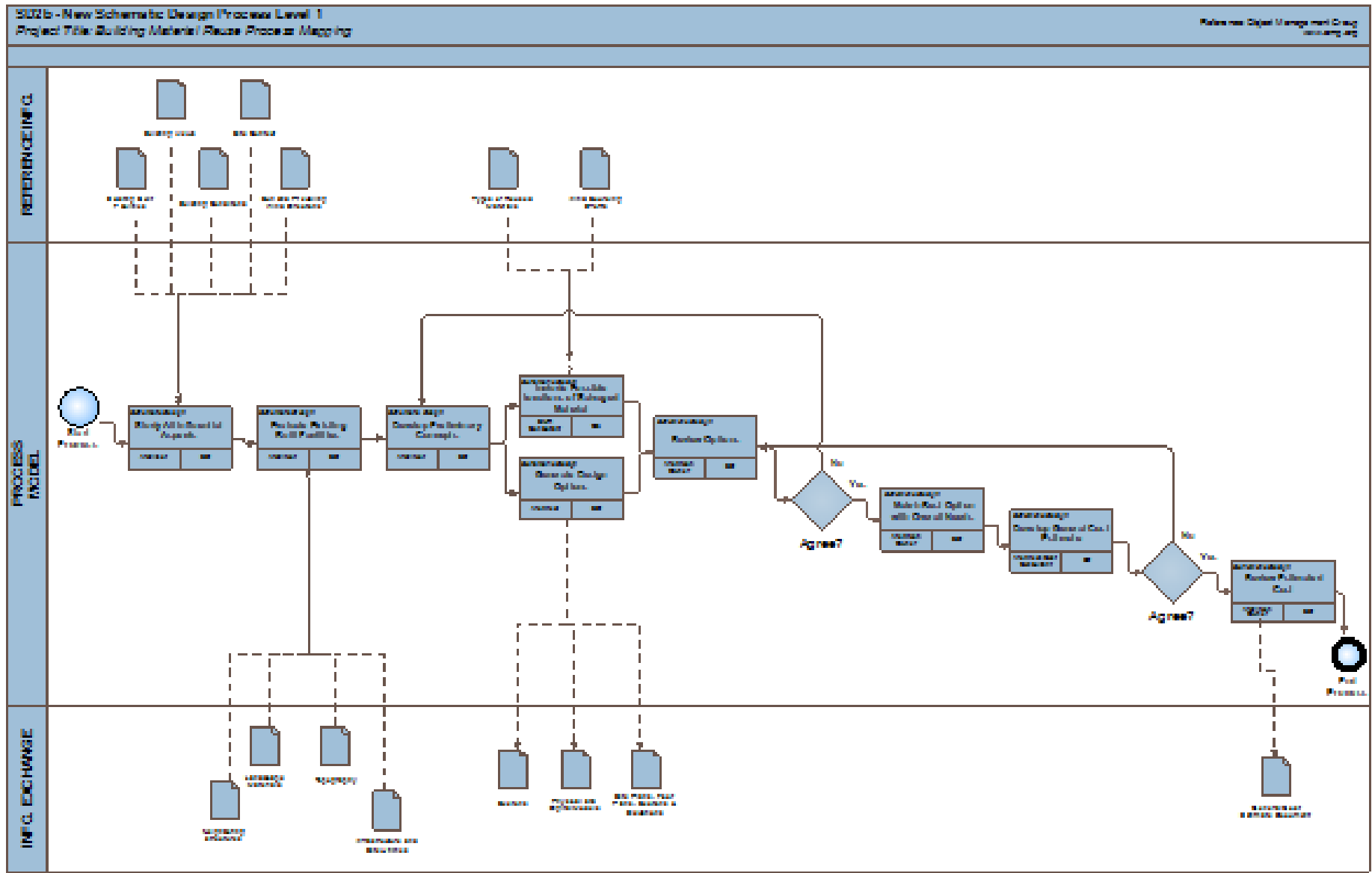




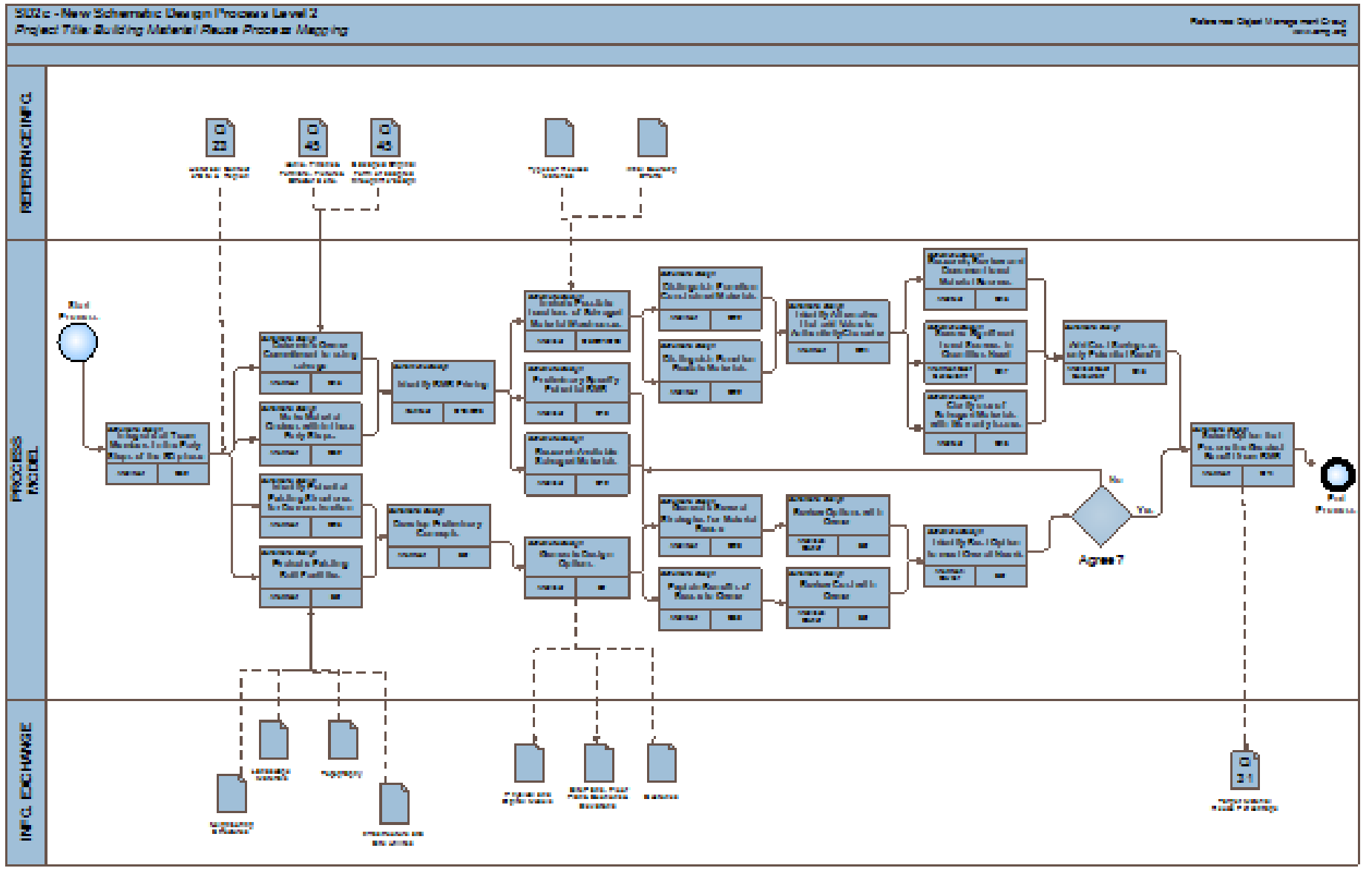

Figure 8. Resource-based schematic design process level 2 (\# SD2c). Source: (Author 2012)

client (concept floor plans, sections, elevations, 3D model), obtaining the client's review and input, and finalizing the schematic design deliverables. Also, a thorough study of zoning, building codes, and regulations is needed. The initial UML activity map was used to develop this level using BPMN after seeking input from the Delphi research focus group. The map addresses typical SD phase activities without incorporating resource reuse decisions.

\subsection{Resource-Based Schematic Design Process Level 1 (SD2b)}

This process starts with defining all influential aspects of the project design. Within this activity, the design team identifies if there are any existing structures on site and their potential for deconstruction, as well as materials that could be harvested. Additionally, part of the data gathered for this process includes an identification of available reclaimed materials within a reasonable proximity so that these can be priced and incorporated into the design. The recent demands on estimating an accurate project budget by the end of the SD phase has led to the selection of primary materials occurring earlier in the process.
Furthermore, design teams propose building systems at the end of the SD phase, since it is too late to expect systems and material discussions to happen during the design development (DD) phase. To achieve this, some architectural firms use a highly integrated method that allows them to typically meet several times during the SD phase with structural, MEP, and civil engineers; landscape architects; and other relevant parties. As a result, all material choices are made early in the process because they impact cost updates, thermal performance, and materials selection. According to the research focus group, Building Information Modeling (BIM) has been an effective medium to facilitate this integration (Fig. 7).

\subsection{Resource-Based Schematic Design Process Level 2 (SD2c)}

At Level 2, the activities of the previous SD levels are expanded. At the information gathering stages, as shown in Fig. 8, a list of potentially salvageable materials from existing on-site buildings is generated. To distinguish between functional reuse versus creative reuse, some of the materials are identified as "function constrained," for example, a set of windows of a particular size would require a specific layout for reuse. 
Other materials are "function flexible," meaning they can be used as finish materials or textures, with the expectation that dimensions can be modified as needed. Examples include doors used as paneling and lumber used as trim. During this phase, the design team also explores ideas for detailing material assemblies to allow for future disassembly. Some relevant reference information, such as the structure's historical context as it relates to surroundings, site, and region are included at the beginning of the process. This information underscores the importance of the in-depth knowledge of the social and economic history of any existing buildings scheduled for deconstruction. In that regard, and before reviewing the cost with the owner, a design alternative is introduced that may exceed the budget but would add significant value regarding preserving the project's character and authenticity. Some of the featured activities within the process include identifying potential material suppliers for reuse, generating several strategies for material reuse, explaining the benefits of resource reuse to the client, and adding to deliverables "target material reuse percentage."

\subsection{Methodological Triangulation of Data and Information}

Triangulation refers to the use of more than one approach to the investigation of a research question in order to enhance confidence in the findings. The term derives from surveying, where it refers to the use of a series of triangles to map out an area (Denzin 1978). It is an analytical approach that integrates multiple data sources to improve the understanding of the research problem and to guide proposed decision-making to address such problems. Triangulation includes not only the comparison of different data sources, but also the use of different data gathering techniques and methods to investigate the same phenomenon. The three sources of data used in the investigation of this research are Literature Review, Case Studies, and Interviews. The qualitative nature of the research in the knowledge capturing process of the data collection was done to compare the results with other sources of data in the sense of triangulation and to carry out checks for reliability and consistency in findings. The qualitative content analysis of the faceto-face survey phase of the knowledge capturing process was used in conjunction with the online surveys and questionnaire to form a Delphi method of consensus with the expert panel. This was taken back to both the selected case studies and the scarce literature to form the grounded theory of the research. The following description is a result from the patterns developed from case studies analysis and the focus group whole text analysis.

- Early integration of BMR concept during pre-design or programing phase

- Engage all project stakeholders in the process from the beginning

- Flexible specifications to accommodate the lack of data, information, and uncertainties

- On and off-site sourcing and vendors networking (Sourcing and VR)

- Flexibility in accepting wide ranges of appearance and availability by all stakeholders

- Phasing and splitting contracts to clarify and define roles and responsibilities

- Indirect matching of materials and components lead to creative design
- Mock ups and samples of materials are essential in making a decision during the design phase

\section{CONCLUSION}

The work presented in this paper is a significant step toward reducing the problem of waste in the building and construction industry. The proposed decision-support framework anticipates a significant societal contribution in reducing nearly $40 \%$ of the total solid waste stream. This paradigm shift requires changing the current traditional project delivery practice toward a circular economy approach. The lack of interest from the AEC industry to embrace resource-based design is due to the lack of structured information on material reuse. This obstacle can now be mitigated by our proposed dynamic knowledgebase and decisionsupport framework. Process modeling offers a clear and systematic methodology that makes design decisions less ambiguous and transfers the knowledge gathered for one project to the next without depending entirely on the tacit knowledge of the project's designers. A resourcebased design-bid-build approach can certainly benefit from the established information systems modeling language. The latter provides the backbone of the information flow to the architect and facilitates more focus on the creative aspects of design. A structured framework such as the one proposed in this study allows for the integration of dynamic decisions, which includes the specific parts, linkages, and networks of such a dynamic system. The resource-based design process, as a system approach, is inherently dynamic, although it is presented as a cause-effect relationship between activities, data, and processes.

The process mapping developed through this study attempted to reorganize the traditional design practice to support the resourcebased design approach. The support of the means oriented approach could only be achieved by translating the design processes into a structured workflow diagrams adopted from the Business Information Technology domain. Through the standardization of language, the integration of the resource reuse process into BIM becomes applicable. This paper demonstrated an example of mapping the SD phase of the DBB project delivery method in multiple layers of complexities. The hierarchy of systems helps in process disambiguation and synthesizes the architecture of complexity. The hope is that architects will find these structured process maps beneficial for streamlining the nearly limitless parts of the resource-based design process.

The study also addressed resource reuse challenges and opportunities, innovative tools, and resources availability, and identified strategies to utilize reused materials as a vehicle for creativity and sustainability. The key to growing resource reuse is building a greater awareness within the building and construction industry. Future research to extrapolate on this work suggests using the building material reuse knowledgebase to build a unified virtual repository database to be connected to all available physical repositories and share a unified standard of information. This virtual repository as suggested should be maintained by a national level organization such as the US BCSD or similar entity. Once the unified virtual repository is integrated with BIM, it can work as a feedback and feed forward support for architects and designers as they consider building material reuse in new designs and constructions. 
This integration will facilitate streamlining the resource-based design process because the backbone workflow of BIM is now informed with the business process modeling of circular design and resource reuse processes.

\section{ACKNOWLEDGMENT}

This paper is a further development of a doctoral research published first by the author in 2012. The author is sincerely grateful to Dr. Ralph Badinelli and Dr. James Jones for their insightful guidance, The Department of Architecture at Texas A\&M University, and the Enquiry Journal editors, Philip Plowright and Jeremy Voorhees for their meticulous and thorough review of this work. 


\section{REFERENCES}

Addis, W. 2006. Building with reclaimed components and materials: a design handbook for reuse and recycling: Earthscan.

AIA. 2007. Defining the Architect's Basic Services. edited by American Insitute of Architects (AIA). AIA.org: AIA Knowledge Resources Staff.

Akinade, Olugbenga O., Lukumon O. Oyedele, Kamil Omoteso, Saheed O. Ajayi, Muhammad Bilal, Hakeem A. Owolabi, Hafiz A. Alaka, Lara Ayris, and John Henry Looney. 2017. "BIM-based deconstruction tool: Towards essential functionalities." International Journal of Sustainable Built Environment 6 (1):260-271. doi: https://doi.org/10.1016/j. ijsbe.2017.01.002.

Ali, Ahmed K., and Ralph Badinelli. 2016. "Novel Integration of Sustainable and Construction Decisions into the Design Bid Build Project Delivery Method Using BPMN." Procedia Engineering 145:164-171. doi: http://dx.doi.org/10.1016/j.proeng.2016.04.038.

CIB. 2002. "Design for Deconstruction and Materials Reuse." CIB Task Group 39 - Deconstruction Meeting, Karlsruhe, Germany, 9 April 2002.

CICRP. 2010. BIM Project Execution Planning Guide Computer Integrated Construction Research Program: Pennsylvania State University.

Falk, Robert H., and Brad Guy. 2007. Unbuilding : salvaging the architectural treasures of unwanted houses. Newtown, CT: Taunton.

Fettig, Tad, Elizabeth Westrate, Mark Decena, John Kenney, Brad Pitt, Kontentreal (Firm), and PBS Home Video. 2006. Design e p2 s the economies of being environmentally conscious. Alexandria, Va.: Distributed by PBS Home Video, videorecording :.

Fletcher, S. L., O. Popovic, and R. J. Plank. 2002. "Designing for future reuse and recycling." Steel in Sustainable Construction: lisi World Conference 2002, Conference Proceedings:287-292

Friedman, Ken. 2003. "Theory Construction in Design Research: Criteria: Approaches, and Methods." Design Studies 24 (6).

Hinte, Ed van, Césare Peeren, and Jan Jongert. 2007. Superuse: constructing new architecture by shortcutting material flows. Rotterdam: 010 Publishers.

Jones, J.C. 1992. Design Methods: John Wiley \& Sons.

Kalay, Y.E. 1987. Computability of design: Wiley.

Knecht, Barbara. 2004. "Designing for Disassembly and Deconstruction." Architectural Record.

Korber, Andrea. 2002. "Productecture: Design for Remanufacturing." Masters, Harvard School of Design

Krygiel, Eddy, and Brad Nies. 2008. Green BIM : successful sustainable design with building information modeling, Sybex serious skills. Indianapolis, Ind.: Wiley Pub.

Lawson, B. 2006. How Designers Think: The Design Process Demystified: Elsevier/Architectural.
Linstone, H.A., and M. Turoff. 1975. The Delphi method: techniques and applications: Addison-Wesley Pub. Co., Advanced Book Program.

Lynch, Kevin, and Michael Southworth. 1990. Wasting away. San Francisco: Sierra Club Books.

Messner, John I. 2003. "An Architecture for Knowledge Management in the AEC Industry." Construction Research Congress: Wind of Change: Integration and Innovation, Honolulu, HI.

Miller, William R. 2004. Definition of Design. In Environmental Systems Research Institute Redlands, California.

Morris, and Matthiessen. 2007. Cost of Green Revisited: Reexamining the fesability and cost impact of sustainble design in the light of increased market adoption. Davis Langdon.

Osmani, M. Glass, J. Price, A. D. F. 2008. "Architects' perspectives on construction waste reduction by design." Waste Management 28 (7):1147-1158. doi: Doi 10.1016/J.Wasman.2007.05.01.

Perdomo-Rivera, Jose Luis. 2004. "A Framework For A Decision Support Model For Supply Chain Management In The Construction Industry." PhD, Environmental Design and Planning, Virginia Tech (etd-11082004152347).

Plowright, Philip D. 2014. Revealing architectural design : methods, frameworks and tools. London; New York: Routledge.

Reekie, R.F. 1972. Design in the built environment: Edward Arnold.

Rhem, Anthony J. 2006. UML for developing knowledge management systems. Boca Raton, FL: Auerbach.

Roberts, J. 2005. Redux: Designs That Reuse, Recycle, and Reveal: Gibbs Smith.

Saleh, Tarek M. 2009. "Building green via design for deconstruction and adaptive reuse." MASTER OF SCIENCE IN BUILDING CONSTRUCTION Text (Electronic thesis) in PDF format, THE GRADUATE SCHOOL OF THE UNIVERSITY OF FLORIDA, University of Florida.

Snyder, James C. . 1970. Introduction to Architecture. New York: McGrawHill Publication.

USGBC. 2003. Reference Package for new Construction \& Major Renovation. In LEED-NC Version 2.1, edited by Leadership in Energy \& Environmental Design.

Venturi, Robert, and Museum of Modern Art (New York N.Y.). 1966. Complexity and contradiction in architecture. With a introd. by Vincent Scully, Museum of Modern Art papers on architecture, 1. New York,: Museum of Modern Art; distributed by Doubleday, Garden City.

Wang, David, and Linda N. Groat. 2013. Architectural research methods / David Wang, Linda N. Groat. Second Edition ed. Hoboken: Wiley.

Woudenberg, Fred. 1991. "An evaluation of Delphi." Technological Forecasting and Social Change 40 (2):131-150. doi: 10.1016/00401625(91)90002-w. 